\title{
Practical and Productive Thinking in Aristotle
}

Preprint, forthcoming in Phronesis, April 2018

\author{
Jozef Müller \\ Department of Philosophy, University of California, Riverside \\ HMNSS Building, Room 1604, 900 University Avenue, Riverside, CA 92521. USA. \\ jozef.muller@ucr.edu
}

\begin{abstract}
I argue that, on Aristotle's account, practical thinking (unlike productive thinking) has as its origin a desire whose object is the very thing that one reasons about how to promote. This means: (a) there is only a contingent relationship between the desire that one practically reasons about how to satisfy and the action one decides on; (b) practical thinking and action (unlike productive thinking and production) cannot be separated from the agent. I also show how my account of practical thinking can shed new light on Aristotle's claim that the virtuous agent must decide on her virtuous actions 'for themselves'.
\end{abstract}

\section{Keywords}

Aristotle; practical thinking; productive thinking; action; production; decision; virtuous action

\section{Introduction}

My aim in this paper is to understand certain features of Aristotle's conception of practical reason, that is, of the kind of reason that he tells us is involved in motivating and guiding human behavior. In two passages, $D A 3.10,432 \mathrm{~b} 26-433 \mathrm{a} 20$ and $N E$ 6.2, 1139a35-b5, Aristotle tells us that, although reason or thought does not initiate movement, ${ }^{1}$ thought of a certain kind does, ${ }^{2}$ namely of the kind

\footnotetext{
${ }^{1}$ In the $N E$ passage, it is 'thought itself' (dianoia autē) that does not initiate movement. In the DA passage, Aristotle refers to 'the reasoning faculty' (to logistikon) and 'that which is called intellect' (nous) (432b26).

${ }^{2}$ In Parts of Animals 1.1, 641a32-b10, considering whether different parts of the soul are origins or principles (archai) of different kinds of change, Aristotle writes that the arche of locomotion might be a part (morion) of the soul that is different from either the nutritive part or the perceptual part. He then goes on to say that the part in question 'is not the thinking part (to noêtikon) since locomotion belongs also to other animals than human beings, but thinking (dianoia) does not' (PA 641b7-8). But, although Aristotle denies that thinking is the principle of locomotion, he does not deny that thinking of a certain sort, or qualified in a certain way (for example, practical thinking as outlined in $D A 3.10$ and $N E$ 6.2) could play the role. This is a familiar move. For example, in the PA passage itself, Aristotle denies that the soul as whole is the principle of change, but
} 
that he calls 'practical' (praktikos). ${ }^{3}$ But what makes practical reason practical? In the DA passage, Aristotle contrasts practical reason with theoretical reason - as the latter is concerned with truth, the former (it seems we are supposed to infer) is concerned with action (praxis). Accordingly, it has become commonplace in the scholarly literature to discuss practical reason in contrast to theoretical reason, sometimes highlighting their differences, sometimes their commonalities. ${ }^{4}$

There is no doubt that the contrast between practical and theoretical reason can illuminate the features of practical thinking that it shares with, or that divide it from theoretical thinking. The trouble is that the feature by which Aristotle distinguishes practical from theoretical reason is the fact that the former but not the latter reasons 'for the sake of something (heneka tou)' (DA 3.10, 433a14). The idea is familiar. Theoretical reason reasons in order to understand or contemplate the truth of what it is thinking and so, to that extent, has its goal in the activity of thinking itself. It is done for its own sake rather than 'for the sake of something' else. Practical thought, however, is goal-directed in the sense that its goal is something beyond its own activity. But although 'being for the sake of something' distinguishes practical from theoretical reason, it is not the feature that makes it practical, since it characterizes not only practical thinking but also productive thinking (e.g. NE 6.2, 1139b1-3; EE 2.10, 1227a11-13; De Caelo 3.7, 306a16). In a way, then, spelling out the contrast between practical and theoretical reason, while illuminating, might not be able to provide us with the right answer to the question of what makes practical reason practical.

maintains that the soul qualified in certain ways (i.e. as its different parts) is the principle of different kinds of change. Similarly, in $N E$ 3.2, after concluding that decision (prohairesis) is not a belief in general (1111b341112a1), Aristotle nevertheless goes on to investigate whether it is not a specific kind of belief. For further discussion of the PA passage, see K. Corcilius, Streben und Bewegen: Aristoteles' Theorie der animalischen Ortsbewegung (Berlin, 2008), 174-6. Still, one upshot of the $P A$ passage is that, minimally, thinking (of any kind) cannot be the principle of locomotion. Since the passage also rules out the perceptual part from playing the role, the lesson seems to be that there is no one part that is the principle of locomotion. For further discussion, see K. Corcilius and P. Gregorić, 'Separability vs. Difference: Parts and Capacities of the Soul in Aristotle', Oxford Studies in Ancient Philosophy 39 (2010), 81-118.

${ }^{3}$ The meaning of the adjective praktikos when applied to reason is not obvious. The basic meaning, suggested by the -ikos ending, is 'productive of action'. But that can mean: (1) that action is the activity of practical thought (in the same way in which theorria is the activity of theoretical reason); (2) that it is thinking that determines which actions one should perform (in the same way in which judges determine which penalties are to be applied); (3) that it is thinking that determines how actions are to be done (in the same way in which productive thought determines how products are to be made); or (4) that it is thinking which is ultimately actualized in action. It can also be a combination of some or all of these possibilities. For a discussion of the issue of translation, see A. Price, Virtue and Reason in Plato and Aristotle (Oxford, 2011), 189.

${ }^{4}$ Most recently, D. Charles, 'Aristotle on Practical and Theoretical Knowledge' in D. Henry and K. M. Nielsen (eds.), Bridging the Gap Between Aristotle's Science and Ethics (Cambridge, 2015), 71-93; J. V. Allen, 'Practical and Theoretical Knowledge in Aristotle' in the same volume, 49-70; or J. Cooper, Pursuits of Wisdom: Six Ways of Life in Ancient Philosophy from Socrates to Plotinus (Princeton, 2012), 74-8. 
In this paper, I propose to investigate practical thinking in contrast to productive thinking. My hope is that it is exactly the right contrast to investigate if one wants to find out what makes thinking or reasoning, on Aristotle's view, practical. As we shall see, the crucial feature is the special connection that such thinking bears to desire. As a general thesis about practical reason, this claim is not particularly surprising. ${ }^{5}$ But $\mathrm{I}$ hope that, by contrasting practical and productive reasoning, I will be able to actually spell out the nature of the connection between reason and desire in practical thinking along with the features of practical thinking that such connection necessitates. The analysis should not only improve our understanding (or dispel various misunderstandings) of Aristotle's theory of practical and productive reasoning (as well as of the related distinction between action and production) but also help us resolve other controversial issues in Aristotle's ethical philosophy. In order to illustrate its usefulness in this regard, at the end of the paper I will turn to $N E 2.4$ where Aristotle explains the difference between merely performing a virtuous action and doing so in a way a virtuous person would do (i.e. virtuously) by drawing certain analogies between the exercise of craft (techne $)$ and virtue. As I will hope to show, once we understand the difference between productive and practical thinking, it becomes possible to offer a new interpretation of the distinction Aristotle has in mind, an interpretation which is both philosophically and textually illuminating.

Before I begin, I should note that the discussion of productive and practical thinking below is not primarily concerned with the perfected states of the capacities for productive and practical thinking, that is, with craft (technē) and practical wisdom (phronēsis). Practical wisdom has, of course, been the target of much discussion in the literature, but it seems to me that it might not always be safe to make inferences about practical thinking from features of practical wisdom that might be special to it.

\section{Productive Thinking}

The primary purpose of productive (poietikē) thinking is to compensate for human beings' lack of natural instruments (PA 4.10, 686a25-b28) by allowing them to use hands (PA 4.10, 687a19-23) to produce whatever instruments they need in order for them to survive and maintain their functioning

\footnotetext{
${ }^{5}$ So already R. D. Milo, Aristotle on Practical Knowledge and Weakness of Will (The Hague, 1966) says that 'desire is involved in the very notion of practical knowledge' (37).
} 
(PA 4.10, 687a23-b4). ${ }^{6}$ Productive thinking is thus primarily concerned with devising ways of producing things that are beneficial or useful in view of our needs (chreiai) (Metaph. 1.2, 982b205). ${ }^{7}$ In its perfected state, it takes the form of craft (technē) which Aristotle describes as a 'state involving true account (logos) concerned with production (poietikēe' (NE 6.4, 1140a10).

An interesting feature of productive thought is that, although one typically engages in it because one wants to make or produce something, productive thinking as such is entirely separable from one's wants, desires or beliefs. One does not need to take into account one's desire to produce a shoe in order to find out how to produce a shoe. Even if one desires to produce it in a particular way, all one needs to take into account are the particular constraints that that way imposes on the production. Insofar as the production of a given artifact (or, at any rate, of a given product) is concerned, one's desires and beliefs play no role. Correspondingly, in its idealized form, productive thinking proceeds through hypothetical necessity: if $\mathrm{A}$ is to be made, then, given what $\mathrm{A}$ is, $\mathrm{B}$ must be done, making no reference to one's desires, preferences, beliefs or values. Unsurprisingly, Aristotle repeatedly connects reasoning through hypothetical necessity to production (Metaph. 7.7, 1032b6-10): ${ }^{8}$

(A) The healthy thing, then, comes to be as the result of the following train of thought: since this is health, if the thing is to be healthy this must first be present, e.g. a uniform state of body, and if this is to be present, there must be heat; and one goes on always thinking in this way until one brings the matter to a final step which he himself can produce. Then the process (kinēsis) from this point onward, i.e. the process towards health, is called production (poiēsis). ${ }^{9}$

\footnotetext{
${ }^{6}$ The locus classicus for Aristotle's distinction between productive, practical and theoretical thinking is Metaph. 6.1, 1025b25. Aristotle also often talks of productive knowledge (rather than thinking), distinguishing it from the two other kinds (e.g. EE 2.3, 1216b16-25; 1221b5-9; Metaph. 6.2, 1026b5).

${ }^{7}$ Aristotle here agrees with Plato, Rep. 341c-e.

${ }^{8}$ See, for example, Phys. 2.9, 199b34-200b8; PA 1.1, 639b19-640a9; and De Motu 701a17-23 (discussed below).

${ }^{9}$ This passage is almost invariably taken to be about deliberation. See, for example, J. Cooper, Reason and Human Good in Aristotle (Indianapolis, 1986), 20-2; D. Charles, Aristotle's Philosophy of Action (London, 1984), 136; C. Natali, The Wisdom of Aristotle, trans. G. Parks (Albany, 2001), 80; N. O. Dahl, 'Contemplation and eudaimonia in the Nicomachean Ethics' in J. Miller (ed.), Aristotle's Nicomachean Ethics: A Critical Guide (Cambridge, 2011), 73; or M. L. Gill, 'Virtue and Reason in Aristotle's Nicomachean Ethics' in D. Henry and K. M. Nielsen (eds.), Bridging the Gap Between Aristotle's Science and Ethics (Cambridge, 2015), 94-110 at 101. But Aristotle does not mention deliberation anywhere in the context (1032a27-b21). Rather, he is discussing generation of things, both natural and artificial (i.e. production). Perhaps scholars have been misled by the similarity that this passage bears to passages such as
} 
An important consequence of this feature of productive thought is that its results - recipes how to produce or make something - are universal (Metaph. 1.1, 981a12-24). They are not tied to any particular individual and are valid and true for anyone who wishes to produce the relevant products and is capable of following instructions about how to do so. In fact, since knowledge that constitutes craft is universal, productive thinking is more like theoria than like praxis: ${ }^{10}$ it contemplates the form of contingent things that lack internal nature from the point of view of their construction or coming to be (NE 6.4, 1140a10-15) and, hence, also their destruction or passing away (Metaph. 9.2, 1046b4-11; NE 5.1, 1129a14-26). ${ }^{11}$ The consequence is that productive thought (and knowledge gained by it) is motivationally inert (Metaph. 9.5, 1048a8-11). Although it is goaldirected thinking, it neither presupposes (or considers) its goal as an object of desire nor provides reasons for making it an object of desire. Such reasons (say, the further use of what one is constructing or the goal one wants to achieve by destroying something) are extraneous to it.

Aristotle makes this clear in Metaph. 9.2, where he distinguishes between rational (meta logou) and non-rational (alogoi) psychological powers (dunameis). He asserts that non-rational powers are 'of one thing', whereas rational ones (i.e. crafts) are 'of opposites' (Metaph. 9.2, 1046b11). A non-rational power works always the same way, producing the same result. Consequently, whenever it is in appropriate circumstances, it is activated and produces the result for

$N E 3.3,1112 \mathrm{~b} 15-27$, in which Aristotle does describe deliberation. But in the $N E 3.3$ passage, he does not state that the form of deliberative reasoning is 'given what $\mathrm{X}$ is, if $\mathrm{X}$ is to come about or occur, $\mathrm{Y}$ must be done' as he does in the passage in Metaph. 7.7. Rather, he says that we search for the means or things that will promote our desired ends and that we do so until we have discovered a particular step or particular steps that we can take ourselves so as to begin the process. He also draws an analogy between a person who deliberates and a geometer who analyzes a diagram (1112b20-4). The point of the analogy seems to be twofold. First, they both reason about how to achieve a preconceived end. Secondly, they both stop inquiring once they figure out the right sequence of actions (or construction moves). Neither point commits Aristotle to deliberation having the form of reasoning by hypothetical necessity. A more careful treatment of the passage can be found in A. W. Müller, Pratkisches Folgern und Selbstgestaltung nach Aristoteles (Freiburg / München, 1982), 46-9; and Price, Virtue and Reason (n. 3 above), 236-46.

${ }^{10}$ For an interestingly different view, see G. Rodier, Aristote: Traité de L'Ame, vol. ii (Paris, 1900), writing that practical reason is, just like theoretical reason, 'purement théorique' (537). For Rodier, practical reason 'ne fait que determiner les moyens propres à atteindre une fin', while the execution of those means is outside of its domain belonging to that of craft (538). Although I disagree with Rodier about the nature of practical reason, including its purely theoretical nature, his contention that craft plays a role in the execution of actions shares some affinities to my treatment of the role of craft (and cleverness) later in the paper.

${ }^{11}$ In this respect, productive thought is similar to the study of coming to be and passing away of natural things - the study of the life-cycle of, say, lions involves the causes of both birth and growth into a healthy individual as well as of sickness, decay and death. Hence, it is no coincidence that Aristotle often draws analogies between generation of natural things and production - they both display the same kind of logical structure, namely hypothetical necessity (e.g. Phys. 2.9, 199b34-200a14). 
which it is a power. A rational power, of which Aristotle's only example is craft, is productive of contrary effects and so it cannot be activated in the same way. If it were, it would produce incompatible results at the same time and that is not possible (Metaph. 9.5, 1048a8-11). Consequently, productive thinking needs to be given a direction - whether it is to operate towards the construction of its product or away from an already constructed product towards its destruction. As Aristotle says, there must be something that sets it towards a particular outcome in the particular circumstances: 'That which directs (to kurion), then, must be something else; I mean by this, desire (orexis) or decision (prohairesis)' (Metaph. 9.5, 1048a10-11).

Before moving on to practical thinking, a quick remark is in order. Although Aristotle tells us that crafts are 'for opposites', he also thinks that every craft has its proper product. Crafts are concerned per se only with one of the opposites, namely, with the positive one (Metaph. 9.2, 1046b10-12). This positive opposite is the goal or purpose for the sake of which a given craft exists - medicine for health, shoemaking for shoes, house-building for houses, and so on. Aristotle's claim is not about causation (as the positive outcome is not necessary), but about explanation. For example, in order to explain why a doctor cures, we do not need mention anything besides her possession of the art of healing. Her activity is fully intelligible from the point of view of her being a doctor and it is a perfectly good explanation of why she heals to say that she does so because she is a doctor. If she were to use of her knowledge to harm somebody, her activity would not be similarly intelligible - one cannot say that she harms because she is a doctor. If she harms, there must be something else, something distinct from her being a doctor, that explains what she does. We will return to this point in more detail towards the end of the paper.

\section{Practical Thinking}

Aristotle maintains that, unlike productive thinking, practical thinking can initiate movement and that this is its distinctive feature. Aristotle characterizes the kind of thinking that can initiate action or, in general, cause one to move in two closely related passages:

(B) Both of these then are capable of originating local movement, thought and desire (nous kai orexis). But thought that reasons for the sake of something (ho heneka tou logizomenos) and is practical (ho praktikos). It differs from contemplative thought in its end (telos). And every kind of desire is for the sake of something (heneka tou pasa). For the very thing that the desire is for is the principle (archē) of practical reason (tou praktikou nou) and the last step [of reasoning] is the principle of action (archē tēs praxeōs). So it is reasonable that these 
two appear as movers, desire and practical thinking (orexis kai dianoia praktikē). For that which is desired (to orekton) moves, that is, thinking moves on its account (dia touto) since (hoti) that which is desired (to orekton) is its principle (archē autēs) (DA 3.10, 433a13-20).

(C) Thought (dianoia) itself moves nothing, but one that is for the sake of something and is practical (hē heneka tou kai praktikē) does. For this thought is also the principle of (archei) productive thought. Every producer produces for the sake of something (heneka tou) where that something is in relation to something and for something [else] and not an end (telos) without qualification (haplōs) which is not something that can be made (to poieton), as opposed to being achieved in action (to prakton). For doing well is the end (eupraxia), and the desire (orexis) is for it. That is why decision (prohairesis) is either thought issuing in desire (orektikos nous) or desire issuing in thought (orexis dianoētikē) (NE 6.2, 1139a35-b5).

In both passages, Aristotle maintains that, although thought (nous or dianoia) itself does not move one to act, thought of a certain kind does, namely one that 'reasons (logizomenos) for the sake of something (heneka tou) and is practical (praktikos)'. What does Aristotle mean by 'for the sake of something' and 'practical'? One possibility is to take the 'and' in 'and is practical' to be epexegetic. ${ }^{12}$ In that case, Aristotle would be saying that the kind of thought that initiates action or moves is one which is done for the sake of action, that is, one whose end (telos) is action. This would distinguish it from the kind of thought that does not move, namely contemplative thought whose end (telos) is truth (DA 3.9, 432b26-9; Metaph. 1.1, 982b20-7).

One problem with this interpretation is that Aristotle usually associates that for the sake of which something is done with the goal or end at which one aims in doing something rather than with that which one does it. ${ }^{13}$ In the case of deliberation (bouleusis) - the paradigmatic form of practical thinking - this association is explicit. Deliberation is about (peri) what to do (i.e. action), but it is done for the sake of (heneka) an end that one aims at (EE 2.10, 1227a5-18):

\footnotetext{
${ }^{12}$ In translation, this view is adopted by R. D. Hicks, Aristotle: De Anima (Cambridge, 1907), ad loc., as well as by K. Corcilius, Über die Seele: De Anima (Hamburg, 2017), ad loc. For a discussion of the implications of adopting the epexegetic reading, see Price, Virtue and Reason (n. 3 above), 189-95.

${ }^{13}$ See, for example, APo. 85b27-86a3; DA 2.4, 415b15-20; NE 3.7, 1115b13-14; 3.9, 1117b2-5; EE 1.8, 1218b10-18; 2.10, 1226a8-17; Rhet. 1363b16-17. For a contrary view concerning passages B and C, see R. A. Gauthier and J. Y. Jolif, L'Éthique à Nicomaque (Louvain-la-Neuve, 2002), 444.
} 
(D) Since one who deliberates always deliberates for the sake of something (heneka tinos), there is always some aim (skopos) in relation to which the deliberator investigates what is useful. And so no one deliberates about the end (telos), this being rather the principle and hypothesis (arche kai hupothesis), just like the hypotheses in theoretical sciences. We have spoken about these briefly in the beginning of this work and in detail in the Analytics. Investigation (skepsis), both one involving and one not involving craft, is about (peri) what promotes the end (pros to telos), for example, when deliberating whether they should go to war or not. But there will first be the reason why (to di' ho), and this is that for the sake of which (to hou heneka), for example, wealth or pleasure or anything else of the sort that happens to be that for the sake of which (hou heneka) [one deliberates]. For the deliberator deliberates, when considered from the point of view of the end (apo tou telous eskeptai), either how he could get hold of what conduces to it [i.e. the end] or what he can do to promote the end. ${ }^{14}$

Another problem is that, if the interpretation were correct, then 'being for the sake of something' would be a sufficient condition for thought to initiate action or movement. But that would make productive thought capable of initiating motion as well. As Aristotle points out at 1139b1-3 (passage C) as well as at 1227a12 (passage D), productive thought is also for the sake of something and since that would mean (on the current interpretation) that it is concerned with production (NE 6.4, 1140a16-17), then productive thought could move one to production. However, it is Aristotle's thesis that productive thought by itself cannot move one to produce anything (e.g. Metaph. 9.2, 1046b4-23).

It thus seems better to take heneka tou and praktikos as two independent characterizations that only jointly explain what kind of thinking can move or cause motion. The meaning of heneka tou seems clear from passage $\mathrm{D}$ - it is a kind of thought in which one reasons about how to achieve some end or goal. The obvious meaning of praktikos would then be that in addition to being for the sake of a goal or end (just like productive thought), the thought is also directed at action, as opposed to, say, production or contemplation. But this obvious meaning is not helpful unless we know what it means for thought to be directed at action. I suggest that Aristotle explicates what it means for goal-oriented thought to be practical in the following way: it is thought whose starting-point or

\footnotetext{
${ }^{14}$ See also EE 2.11, $1227 \mathrm{~b} 36$.
} 
principle $(\operatorname{arch} \bar{e})$ is a desire whose object is the very thing that one reasons about how to promote (passage B at 433a15-17).

In order to see the significance of this feature of practical thought, we need to distinguish the roles played by heneka tou and archē in relevant contexts (passages B and C). As we shall see, the distinction has important implications for Aristotle's understanding of the difference between productive and practical thinking and, consequently, between action and production. It can be best brought out by an example. The basic premise goes as follows. Luca asks his friend Joe who is a house-builder to figure out for him how to attach an additional room to his house. Since Joe wants to help his friend, he devises a plan for Luca that, once enacted, would do the job.

Let us start with Joe. First, his productive thinking starts from the idea of the additional room in Luca's house. This is that for the sake of which (heneka tou) he (productively) reasons. But, although it is what he productively reasons about, it is not what moved him to think about it. It does not explain why Joe engages in productive thinking about it. After all, Joe does not want the room at all even though he wants to figure out how to make it. Rather, he wants to help his friend Luca, and that desire (to help) is what got him thinking about the room. It is the arche (principle) of his thinking since it explains why he engaged in the thinking that he did..$^{15}$ In sum, the end or goal of productive thinking (i.e. that for the sake of which one reasons) and that which motivates one to think productively turn out to be two distinct things. In a way, this should not be surprising - it is the lesson of Met 9.2 and 5 discussed at the end of the previous section.

Secondly, Joe's productive thinking about how to construct the room (where the construction is the heneka tou of that thinking) is best understood as initiated by his decision rather than just a desire to work out the plan in order to help Luca since, presumably, his desire to help Luca is a long-standing feature of his friendship with him rather than an occurrent desire tied to the occasion. We can put the matter in this way - Joe desires to help Luca (S1) and so decides to work out a plan for the additional room (P1). Notice that, for Joe, his action (P1) is a way of doing what he desires to do (S1). What led him from the initial desire $\mathrm{S} 1$ to his decision for P1 is practical reasoning. Interestingly, what Joe thought about practically (heneka tou), namely how to help his friend, is the very thing that he wants to do and that explains (i.e. is an $\operatorname{arche}$ ) why he is thinking about it. The identity of what one reasons about with the reason that explains why one reasons about it is a particular feature of practical thinking. We can see this feature present also in Luca's decision

\footnotetext{
${ }^{15}$ In passage D, Aristotle compares the role of archē to that of hypotheses in theoretical sciences: they are explanations that give the reason why (APO. 85b28-86a3).
} 
(i.e. the result of Luca's practical thinking) to build the additional room (P2). Assuming that Luca is a standard rational agent, he must have decided to build the room for some reason or purpose. For example, he wanted to make the life of his growing family more comfortable (S2). This purpose is both that for the sake of which (heneka tou) he reasoned (i.e. what he was thinking about how to promote or achieve) but also that which explains (is an arche for) why he engaged in thinking about how to promote it. Luca is thinking about how to make the life of his family better because that is what he wants to do.

In sum, in practical thinking, the archē of one's thinking (that which explains why one engaged in a particular episode of thinking), is a desire for the very thing that one reasons about or for the sake of (heneka tou). In productive thinking, they come apart: what one reasons about (heneka tou) and what gave rise to and explains why one is thinking about it (archē) are distinct. It will be useful to summarize the results of our analysis of the example in a table:

\begin{tabular}{|c|c|c|}
\hline & Practical Thinking & Productive Thinking \\
\hline Luca & $\begin{array}{l}\text { Goal (heneka tou): making the life of his } \\
\text { family more comfortable. } \\
\text { Result: decision to build an additional room. } \\
\text { (P2). } \\
\text { Principle (arch } \overline{\text { e }} \text { : desire to make the life of } \\
\text { his family more comfortable (S2) }\end{array}$ & (Outsourced to Joe.) \\
\hline Joe & $\begin{array}{l}\text { Goal (heneka tou): helping his friend Luca } \\
\text { Result: decision to work out the plan (P1). } \\
\text { Principle (archēe): desire to help Luca (S1). }\end{array}$ & $\begin{array}{l}\text { Goal (heneka tou): additional room for } \\
\text { Luca's house (R). } \\
\text { Result: construction plan (W) for (R) } \\
\text { Principle (archēe): decision to work out the } \\
\text { plan (P1) in order to help Luca (S1). }\end{array}$ \\
\hline
\end{tabular}

The example allows us to observe yet another difference between practical and productive thinking: unlike practical thinking, productive thinking can be outsourced to someone else. Joe's decision (the result of his practical thinking) is followed by productive thinking about how to construct the room. But, although Luca's decision (to build the room) requires that such thinking be done, Luca outsourced it to Joe. ${ }^{16}$ Notice that this implies that productive thinking does not bridge

\footnotetext{
${ }^{16}$ Although there is no explicit discussion of this idea in Aristotle, it is clearly present in his discussion of the way in which the slave is supposed to know (epistasthai) how to execute or produce (poiein) that which the master orders (epitattein) so that the master need not himself engage in the actual production of (including
} 
the gap between one's initial desire for something and one's decision but, rather, stands apart from the thinking that does (i.e. practical thinking). We can clearly observe its place on Joe's case - his productive thinking is part of his action. It is what he decided to do in order to help Luca. ${ }^{17}$ This is not a coincidence. In passage $\mathrm{C}$, Aristotle already told us that practical thought is the principle of productive thought while in passage B he insists that the conclusion of practical thought (decision) is a principle of action. De Motu offers a clear illustration (De Motu 701a17-23):

(E) (1) I need a covering and a coat is a covering. I need a coat. What I need I have to make and I need a coat. I have to make a coat. The conclusion 'I have to make a coat' is an action (praxis). And one then acts from the principle (archē). (2) If there is to be a coat, there must first be this, and if this then this — and straightaway one does this. ${ }^{18}$

$\mathrm{E}(1)$ refers to reasoning that starts from one's realization that one needs a covering and ends in a decision (here referred to as 'conclusion') to the effect that one will make a coat. This is reasoning about what to do vis-à-vis one's need or desire. Once it is concluded, it is followed by an action (done from one's decision) which includes productive reasoning $(E(2))$ about how to make the coat. Productive thinking is here thought of as part of one's action that follows one's decision. As Aristotle has already told us, there must be something else that activates productive thinking and this can be either desire or decision (Metaph. 9.5, 1048a10-11). And if decision is the principle of action, then productive thought can and in fact does occur as part of action.

There are two objections to the claim that the special feature of practical (but not of productive) thinking is that its arche (that which explains why one engaged in the particular episode of thinking) is a desire for the very thing that one reasons about or for the sake of. Answering them will help us sharpen the account. First, could there not be a case in which one's thinking about how to, say, construct a model of a ship in a bottle is motivated by the desire for doing just that (i.e. it is

productive thinking about) whatever he needs to be done but focus on politics and philosophy (Pol. 1.7, $1255 \mathrm{~b} 30-40)$.

${ }^{17}$ It would be a mistake to think that Joe's productive thinking just is his action. Joe's action includes working out the construction plan, but such thinking is embedded in the context of his decision to work out the plan for Luca. His action, in other words, involves not only the actual productive thinking about how to construct the room, but also, among other things, his aim to do so for Luca and, presumably, giving the plan to Luca. These latter features of Joe's action are not part of his productive thinking as such.

${ }^{18}$ My understanding of this passage owes a great deal to A. Price, 'Choice and Action in Aristotle', Phronesis 61 (2016), 435-62. 
one's hobby, something one likes to do)? In such a case, would not that which one productively reasons about be the same thing that motivated one to think about it? Secondly, one might think that sometimes figuring out how to produce or make something is crucial to deciding whether or not one wants to produce it. Hence, productive thinking can be part of one's practical thinking rather than stand apart from it.

We can begin by observing that, in practical thinking, there is no necessary connection between the initial desire and the action decided upon as a way of satisfying it (i.e., in the example, between $\mathrm{S} 1$ and $\mathrm{P} 1$, and $\mathrm{S} 2$ and $\mathrm{P} 2$ ). It is a matter of various contingent factors of a particular case for example, Joe's abilities, desires and beliefs, Luca's circumstances and needs - that it is P1 that will do as a way of doing or achieving S1. At another time, S1 might be fulfilled by, say, lending Luca some money or cooking him a nice meal. ${ }^{19}$ The same holds for S2 and P2: Luca could have decided to make the life of his family comfortable in many different ways. Practical thinking is a search for what will satisfy a desire ${ }^{20}$ and there are, potentially, infinitely many ways in which that can be done. ${ }^{21}$ In fact, it is even possible to decide to do something in view of one's desire for some end which is in no way conducive to that end but, nevertheless, manages to satisfy the desire. For example, Randy feels like having some salted nuts but he cannot find any at home. Since it is too late (Randy thinks) to go out and buy some, he decides to have some tea instead of the nuts. There is nothing unintelligible about Randy's decision to have tea as a way of satisfying (or perhaps dealing with) his initial desire for salted nuts. Yet it would be, if we were to insist that the action or means chosen or decided upon must be, somehow, necessarily connected to the initial end or object of that desire.

This means that practical thinking need not involve any sort of necessity, whether it be deductive or hypothetical necessity. ${ }^{22}$ In fact, it also might not involve considerations of efficiency,

${ }^{19}$ As Aristotle says, we deliberate about what comes about through our agency 'but not always in the same way' (NE 3.3, 1112b3).

${ }^{20}$ Nothing Aristotle says requires that the agent is conscious of the desire in his deliberation or practical thinking. All he requires is that the agent sets him- or herself a goal $(N E 3.3,1112 \mathrm{~b} 15-16)$ and that he or she desires it (NE 3.5, 1113b3-5).

${ }^{21}$ For this point, although arrived at by a different route, see Allen, 'Practical and theoretical knowledge in Aristotle' (n. 4 above), 65.

${ }^{22}$ Perhaps the most explicit expression of the idea that it involves deductive necessity is A. Mele, 'How to Represent an Aristotelian Deliberation Syllogistically', New Scholasticism 59 (1985), 484-92, attempting to construct 'a formally valid syllogistic schema for representing bouleusis' (486). For hypothetical necessity, see, for example, Rodier, Aristote: Traité de L'Ame (n. 10 above), 537; and M. Nussbaum, Aristotle's De Motu Animalium (Princeton, 1986), 172. 
optimality or even permissibility of what one (ultimately) decides to do. In thinking practically, one is inquiring into how to satisfy one's desire and that might mean, in the simplest case, no more than finding $a$ way that satisfies it - as when one decides that a coat will do as a covering (passage E) since, perhaps, that's the only thing one could quickly think of (even if, say, a jacket or a sweater would do too). Whether or not one's practical thinking takes a more complex or more reasoned form depends, crucially, both on the kind of person one is and on the kind of situation and state that one is in. It is one's character, among other things, that determines the criteria by which one chooses what counts as a good thing to do, and it is one's current state, among other things, that determines what options are possible (De Motu 701a24-5). For example, if one is a meticulous sort of person, one might not be satisfied with finding a way to do what one desires to do but, rather, inquire into whether there are more ways to do so and which one is the most efficient; if one is a virtuous person, one might inquire into which way is the most $k a l o n ;{ }^{23}$ but if one is too tired and the desire is rather simple (such as hunger), one might not be even willing to consider any option beyond the first one that will do. ${ }^{24}$

A related, equally important point is that practical thinking cannot proceed without desire. Even in passage $\mathrm{E}(1)$ above, there is nothing necessary about deciding for a coat as the covering

${ }^{23}$ It is likely that practical reasoning of the practically wise agent has special features - for example, it is aimed at the right aim (i.e. at what is truly good); it knowingly chooses the right means for the right reasons (NE 6.9, 1142b29-33); and it is well-integrated with the rest of the agent's goals and values. In this sense, the practically wise person is distinguished by, among other things, having understanding of the goodness of his or her aims and actions.

${ }^{24}$ Scholars are often attracted to a much more stringent interpretation of Aristotle's conception of practical thinking. There seem to be three reasons for this inclination. One reason (already discussed) is that they erroneously treat passages in which Aristotle discusses productive thinking as pertaining to practical thinking (e.g. A, E2). Another reason is Aristotle's tendency to make use of practical syllogisms (or syllogistic vocabulary) in contexts where he discusses practical thinking. This tendency has suggested to at least some scholars that Aristotle requires some sort of logical (perhaps deductive) validity for practical reasoning. I do not have space to do justice to the complexities of interpreting practical syllogism and its relation to deliberation. But it seems to me that where it occurs, it usually connects the result of deliberation with action (as in $N E 7.3,1147 \mathrm{a} 25-35$ ) or that it is used to illuminate various features of practical thinking (since, presumably, syllogistic vocabulary is the most exact vocabulary Aristotle has to describe thinking). So, for example, in NE 6.9, 1142b22-26, Aristotle talks of 'false inference (syllogism)' and 'false middle term' in relation to errors in deliberation. But, despite the vocabulary, the passage does not commit him to a conception of deliberation as consisting of (practical) syllogisms. Rather, it illustrates that sometimes, say due to lack of knowledge, we correctly connect two things (desire for an end and action) but in a wrong way. For example, wishing to buy a gift for a friend that she would like, I decide to buy her tickets to the opera thinking that since she loves singing, night at the opera is the right gift. But it turns out that she hates opera-style singing and so my reason for choosing opera was bad. Nevertheless, she is pleased with the gift because, even while she does not like the singing style, she really enjoys the beautiful productions and music of operas. For full discussion of the issue, see Price, Virtue and Reason (n. 3), 236-252; and K. Corcilius, 'Praktische Syllogismen bei Aristoteles', Archiv für Geschichte der Philosophie 90, 247-297. 
that one needs. What makes it the case that one goes from realizing the need for covering to selecting a coat (rather than anything else) is, presumably, that one makes a judgment to the effect that a coat will do, where this judgment is based not only on the actual suitability or availability of a coat as covering but also on one's relevant personal preferences, likes, beliefs and circumstances. Moreover, if one needs a covering and there are two or more options available of which one is aware (say a blanket or a piece of clothing), there might not be a reason necessitating any one of them (i.e. any particular conclusion) and one's reasoning needs to be moved into a particular direction by one's desire or preference. ${ }^{25}$ Practical reasoning thus depends on one's character (broadly speaking as including one's likes, preferences, desires and relevant beliefs) not only insofar as that determines its particular shape or direction, but also insofar as it frequently requires desire to proceed from one step to another. The same is not true of reasoning that displays formal validity or involves necessity. Although there must be something - for example, a wish - to initiate an episode of theoretical thinking, ${ }^{26}$ the ensuing process of thinking (i.e. the actualization of the capacity to think) does not require any further desire to keep it going as long as there is no need to decide between two or more options in which one's thinking can go. ${ }^{27}$

There is perhaps no particular text in Aristotle that suggests this feature of practical thinking explicitly, but consider how in De Motu 701a31-3 Aristotle describes the activity of desire as taking the place, as it were, of reasoning or questioning - the desire for a drink moves one to act once cognition (whether perception or imagination or thought) recognizes a drink - the idea being that one could of course go further (for example, asking whether it is a good drink and so on) but desire now 'decides' that that drink will do. Similarly, in NE 6.2 he tells us that the archē of decision is desire (orexis) and goal-directed reason (logos ho heneka tinos). One might well take it to mean that the role of desire is not just to initiate reasoning but also to guide it all the way to the final act of decision. ${ }^{28}$ It is worth noting that, noticing this feature of practical thinking, Aquinas

\footnotetext{
${ }^{25}$ For a similar point, see Price, Virtue and Reason (n. 3), 249.

${ }^{26}$ For an account of the initiation of episodes of thinking, see K. Corcilius, 'How are Episodes of Thought Initiated, According to Aristotle?' in G. Van Riel and P. Destrée (eds.), Ancient Perspectives on Aristotle's De Anima (Leiden, 2010), 1-15.

${ }^{27}$ For example, in De Motu, Aristotle tells us that 'whenever one thinks two propositions, one thinks and puts together the conclusion' (De Motu, 701a10-11). The presupposition here is, of course, that the two propositions are related in such a way that a conclusion follows of necessity.

${ }^{28}$ Here I agree with Charles, 'Aristotle on Practical and Theoretical Knowledge' (n. 4), 73-78 who argues that wish is present throughout the deliberative process, even though not for the reasons he induces, namely not because, as he claims, there is an identity between 'a rational desire to do A and the desiderative thought that A is to be done' (75).
} 
assigns the task of moving practical thought in selecting among the many options available to the will of the one who thinks practically: 'since the will moves itself by means of deliberation, and deliberation is a non-demonstrative kind of inquiry that can go in different directions, the will moves itself not necessarily. ${ }^{29}$

Now, Aristotle distinguishes practical thinking so understood - that is, thinking that leads to decision about how to satisfy a desire - from thinking about how to realize the action that one has already decided upon. Although he does not draw the contrast explicitly, he describes a perfected capacity to engage in such thinking (i.e. about how to realize an action one has already decided upon), distinguishing it from a perfected capacity for practical thinking (i.e. practical wisdom) as well as virtue (NE 6.12, 1144a20-9):

(F) Virtue, then, makes the decision correct. But whatever should be naturally done for the sake of (heneka) [executing] the decision is not the concern of virtue but of another capacity. We must speak more clearly to gain understanding about them. There is indeed a capacity that they call cleverness (deinotēs). This is such that it makes one capable of doing and attaining the actions that promote whatever goal is assumed. If, then, the goal is fine (kalos) cleverness is praiseworthy, whereas if it is base, it is unscrupulousness (panourgia). This is why both practically wise and unscrupulous people are said to be clever. Practical wisdom is not this capacity [i.e. cleverness] although it does not exist without it.

Cleverness, as Aristotle portrays it in the passage, is a kind of expertise, but in a very general sense of the word. There is no particular form it needs to take or a particular goal it needs to have since what is required of it depends entirely on the kind of action one has decided upon and the particular circumstances in which one must or wants to carry it out. For example, if one decides to impress one's visitors by a great dinner, one has to know how and what to cook for the occasion, whereas if one decides to ask one's provost for a favor, one has to be able to present one's case in the right sort of words. ${ }^{30}$ In some cases, the expertise required is of the sort provided by one's knowledge of a

\footnotetext{
${ }^{29}$ Quaestiones disputatae de malo 6.1: cum ergo voluntas se consilio moveat, consilium autem est inquisitio quaedam non demonstrativa, sed ad opposita viam habens, non ex necessitate voluntas seipsam movet. See also Summa Theologica IaIIae, 6.2.

${ }^{30}$ Many scholars think, mistakenly, that cleverness is practical wisdom without virtue. For example, Gill, 'Virtue and Reason' (n. 9 above), 109 asserts that 'reasoning without virtue is mere cleverness, not practical wisdom at all'. See also, among others, N. Dahl, Practical Reason, Aristotle, and Weakness of Will (Minneapolis, 1984), 63; C. D. C. Reeve, Practices of Reason: Aristotle's Nicomachean Ethics (Oxford,
} 
craft. So in our example of Joe and Luca, it involves knowledge of house-building since it involves working out a plan (W) about how to construct the additional room (R). In general, cleverness involves technical or productive reasoning that proceeds, at least ideally, through hypothetical necessity and does not depend on the character of the one who reasons. The result of such reasoning is a recipe or a set of instructions about how to produce or accomplish something. In contrast, practical reasoning depends on one's character (broadly speaking) and does not involve reasoning through hypothetical necessity, since the connection between S and P (i.e. the desired goal and what promotes it) is contingent.

The answer to the first objection, then, is that sometimes what one decides to do (e.g. to construct a ship in a bottle) is itself an instantiation of the kind of activity that one desires to do (constructing bottled ships). This happens, when one has a very specific desire that already singles out a particular sort of activity. But this is a feature of the example rather than of the general relationship between the object of one's initial desire and the action that one decides on in order to satisfy it. Moreover, even in that case, there are two pieces of reasoning involved. There is practical reasoning that led to the decision to construct a ship in view of one's desire to do so, and there is productive thinking about how to construct the ship, initiated by one's decision. If what we said

1992), 85-6. This view is based on the analogy between natural virtue and cleverness that Aristotle draws in $N E$ 6.13, and on a misunderstanding of what Aristotle means by natural virtue. In particular, natural virtue is taken to be something that transforms into real virtue (once knowledge is added), itself disappearing in the process. But this is not what Aristotle says. Rather, natural virtue is an innate proclivity to immediately feel in certain ways or be attracted to doing certain actions without such actions or feelings flowing from any yet consciously adopted values, goals or attachments. These natural proclivities often remain present even as one acquires full-fledged character qualities or even master virtue. One can, for example, be always prone to anger, to eating sweets or to being generous. Master virtue is having such (good) characteristics too but in another way - it is, among other things, the ability to correct for immediate impulses due to such natural proclivities through reasoning and mature desires habituated to follow reasoning. Hence, even if we have natural virtue, 'we are nevertheless searching for something else to be the master goodness (to kuriōs agathon), that is, to have these [virtues] in another way (allon tropon)' (NE 6.13, 1144b6-8). Aristotle probably thinks that without some (or a significant) degree of natural virtue one cannot acquire master virtue, but that is not the same as thinking that natural virtue is fully transformed into master virtue. He is quite clear that, just as cleverness and practical wisdom are two conditions that coexist in the part that has beliefs (doxastikon) and, although connected, are distinct capacities, so natural and master virtue are two conditions that coexist in the part that is responsible for one's character $(N E 6.5,1144 \mathrm{~b} 14-17)$. One can usefully think of natural virtue as accounting for, among other things, the variability of character-differences between virtuous people. Plutarchus and Andronica are both virtuous individuals, but while Andronica tends to be the friendlier of the two, Plutarchus tends to be the more patient. The point of the analogy between natural virtue and cleverness (which unlike natural virtue is acquired), then, is just that both need a master virtue (one virtue of character, the other practical wisdom) in order to be truly beneficial to the agent. For an interesting discussion of the relationship between natural and master (or perfect) virtue (which also maintains that natural virtue survives into adulthood) see S. A. White, 'Natural Virtue and Perfect Virtue', Proceedings of the Boston Area Colloquium in Ancient Philosophy 8 (1992), 135-68. 
before is true, then the relationship between the initial desire and the decision should be contingent, despite appearances. And this seems to be true. It is conceivable that one could decide to do something else than to construct a bottled ship in view of one's desire or interest in constructing ship. For example, if one did not have the necessary materials for a ship, one could construct a model of a house or decide to paint the bottle inside (rather than construct something in it) instead. ${ }^{31}$ In this case, one would be thinking (productively) about how to construct a model of a house or paint the bottle even if one's initial desire was for a bottled ship.

The answer to the second objection is that, although sometimes one has to find out how something can be produced before one can decide to do so, such reasoning (about how to produce it) is not part of one's practical reasoning that culminates in one's decision. Consider deliberation about whether to build a dam in order to provide electricity for a large city (say, Las Vegas). The requisite decision presumably will involve considerations of how such a dam could be built. But figuring that out is not deliberating - it involves, perhaps, drawing plans, considerations of building options, materials and so on. It is an analysis that can be prepared by someone other than the person who makes a decision. So even Luca could have postponed his final decision until he saw Joe's plans, outsourcing productive reasoning to him. But he cannot outsource his practical reasoning nobody but he can make his decisions. ${ }^{32}$

The foregoing account enables us to shed considerable light not only on the difference between practical and productive reasoning but also on the often discussed distinction between action and production. ${ }^{33}$ First, not only productive reasoning but also production can be outsourced to someone else. However, practical reasoning and action are not similarly transferrable to someone else. For example, one can make a decision to build a house but delegate the actual building to someone else, and, despite the fact that the person who made the decision is not performing the actual building, the building of the house is still something that the person who made the decision does. This is reflected in linguistic practice - one can say that one is building a house even though one is not the person who is actually putting the bricks together. However, one cannot delegate the decision to build to someone else and still remain a person who is building. This is so even if one

\footnotetext{
${ }^{31}$ In a similar way, one can be hungry and feel like having Italian pasta but, in view of not having any available, decide to have some couscous instead.

${ }^{32}$ It should be obvious by now that it is a mistake to treat practical and productive thinking as if they were somehow identical in nature, differing only in the way in which their objects are specified. Yet, this mistake is common in the literature. See, for example, Milo, Aristotle on Practical Knowledge (n. 5 above), 37; M. Johnson, Aristotle on Teleology (Oxford, 2005), 213.

${ }^{33}$ For example: NE 6.4, 1140a16-1140b7; or Pol. 3.4, 1254a5.
} 
should, say, finance the building - an investor is not the same person as the builder (unless

incidentally). Secondly, many people can participate in one production even while they are engaged in different actions. Both Luca and Joe can claim that they are building a room. Luca can do so if he is neither the builder nor the architect because he made the decision that it be built. Joe too can say that he is building a room because he is doing the actual building (or planning). However, they are engaged in different actions even though those actions both include the same production, namely building a room: one action aims at (and so is a case of) making the life of Luca's family better, the other at (and so is a case of) helping Luca. ${ }^{34}$

\section{Virtuous Action Done Virtuously}

I would like to conclude the paper with an example of how grasping the correct conception of practical thinking in Aristotle can help us illuminate other issues in Aristotle's ethics. In NE 2.4, Aristotle makes a distinction between virtuous actions and virtuous actions done virtuously. The distinction is supposed to address an objection to his account of virtue acquisition through habituation. The account, outlined in $N E 2.1$, is as follows. First, Aristotle claims that virtue is acquired through habituation (1103a25-6). Secondly, he assumes (implicitly) that habituation is a process in which one develops the ability for and enjoyment of a certain activity through a repeated performance of that activity. Thirdly, he observes that this is the way in which we learn a craft: we

${ }^{34}$ All this suggests that when in $N E 6.5,1140 \mathrm{~b} 3-4$ Aristotle says that 'action and production are of different

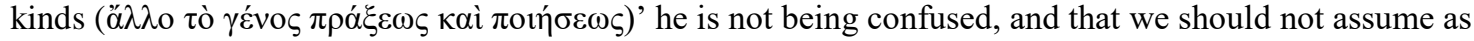
unproblematic J. L. Ackrill's claim that 'actions often or always are productions and productions often or always are actions' ('Aristotle on Action', Mind 87, 1978, 595-601 at 595), or even the more cautious claim of R. Heinaman, that 'an individual action which is a production might be a praxis as well' ('Activity and Praxis in Aristotle', Proceedings of the Boston Area Colloquium in Philosophy 12, 1996, 71-111 at 103). For further discussion of the issue, see Müller, Praktisches Folgern (n. 10 above), 209-30; D. Charles, 'Aristotle: Ontology and Moral Reasoning', Oxford Studies in Ancient Philosophy 4 (1986), 119-44; C. Natali, 'Activité de Dieu et activité de l'homme' in his L'Action efficace: Études sur la philosophie de l'action d'Aristote (Louvain-La-Neuve, 2004), 77-108; and T. Angier, Technē in Aristotle's Ethics: Crafting the Moral Life (Continuum, 2010), 36-58. It is beyond the aim and scope of this paper to pursue the question of the difference between action and production further. However, it can be remarked that if my argument has been correct, both Müller's thesis according to which 'under different descriptions, one and the same human activity can be classified simultaneously as making or acting' (221) and Angier's contention that Aristotle's distinction between actions and productions does not concern two mutually exclusive classes of activity but, rather, 'two mutually exclusive modes of evaluation' (44) are (in different ways) missing the mark. Natali, who thinks of productions in strict parallel to natural generations as consisting of 'une série de passages nécessaires à la realization de la fin' (83) comes closer (though not close enough) when he asserts that 'l'action n'est pas identique au movement, mais elle est composée de mouvements; en cela, elle sa différencie de la poiesis, qui a une structure identique à celle du mouvement' (91-2). Finally, although I am in agreement with Charles (as cited above) insofar as we both think that productions and actions are different types of events, his way of understanding and arguing for the claim (employing the distinction between activities and processes) is quite different from the one advanced here. 
do so by performing the activities of the craft: for example, we learn to play a lyre by playing one (1103a32-4). He concludes that virtue too, just like any craft, must be acquired by performing the activities of a given virtue: we become courageous by performing courageous actions, just by just actions, and so on (1103a34-b2).

One could raise a number of objections to this argument. For example, one could wonder whether repeated performance or engagement in a certain activity might not also engender a dislike for it (rather than making one enjoy it); or one might wonder whether habituation means the same thing in relation to virtue as it does to craft, if, as Aristotle insists elsewhere, craft is a certain kind of knowledge (i.e. a state of the rational part of the soul, such that it should be learned rather than acquired by habit), while virtue is a state of the non-rational part of the soul. In $N E 2.4$, however, Aristotle raises a different worry, namely that someone might think that in order to knowingly perform virtuous actions one already must be virtuous. One might think this because it seems, following the analogy with craft Aristotle introduces, that unless one does such actions by chance or by following someone else's instructions without knowing what one is doing, ${ }^{35}$ one can only do them if one has the appropriate knowledge according to which one acts. But if that is so, it seems that one is already virtuous. What more can there be to one's being virtuous than having the appropriate knowledge and exercising it in action $?^{36}$

Aristotle's response hinges on distinguishing virtuous actions from virtuous actions done virtuously (1105a29-30). Virtuous actions are those that have 'the right qualities' (NE 2.4, 1105a29), whereas virtuous actions done virtuously involve three further features. The agent who performs them must: (1) have knowledge; (2) decide on them and do so for themselves; and (3) do them from a firm and unchanging state (NE 2.4, 1105a30-3). I will set condition (3) aside for the present purposes and concentrate on (1) and (2). First, what knowledge does Aristotle have in mind in (1)? He suggests that (1) 'counts for nothing or for only a little' (1105b2-4), yet he still includes

\footnotetext{
${ }^{35}$ Aristotle is quick to point out that producing something grammatical or musical can happen by chance or by following someone else's instructions. A grammarian or a musician, however, must also possess the appropriate knowledge and produce the appropriate results in accordance with it (NE 2.4, 1105a21-6). As he goes on to say, however, this does not hold in the same way for virtues (1105a26). The discussion that follows (1105a26-b5) thus addresses a version of the initial objection that presupposes that the person in question (one who performs a virtuous action) is not performing it by chance or by following someone else's instructions without knowing what he or she is doing.

${ }^{36}$ Sukaina Hirji reminds me that my reading of the way in which the puzzle is set up in $N E 2.4$ is not entirely uncontroversial. A recent examination of the issue can be found in M. Jimenez, 'Aristotle on Becoming Virtuous by Doing Virtuous Actions', Phronesis 61 (2016), 3-32.
} 
it among the conditions. How can the requisite knowledge (whatever it is a knowledge of) be so insignificant for having a virtue and yet be among the conditions for acting virtuously?

Secondly, what does it mean to say that one has to decide on virtuous actions 'for themselves', and why should deciding on them in that way be ethically significant? When one takes one's own life in order to save one's family, one is surely not deciding to take one's own life for its own sake but, rather, for a particular further purpose (namely, preserving the life of one's family). Perhaps one could reply that one decides on the action (of taking one's own life) because it is the virtuous or right or noble thing to do and that that is what Aristotle means by deciding on the action 'for itself'. Although this is not an obvious meaning of the expression 'for its own sake', we can put that aside for the moment. A more pressing problem is that it implies that what made a person act virtuously (rather than merely performing a virtuous action) was her thought that what she was doing was the right thing to do. This seems false - what made her action virtuous was that it was the right thing to do and what made her act virtuously was that she acted on the right reasons and not that she thought that her reasons were the right ones.

It will be best to tackle the issue by first thinking about how Aristotle can distinguish between actions and the reasons that one has for performing them. Standardly, Aristotle thinks of the reason or reasons one has for performing an action as of the goal or end that one aims at by performing it. He also thinks that one can characterize the action one performs apart from the goal for which one performs it. For example, he says (EE 2.11, 1228a2-17):

(H) We judge a person's character from his decision, that is, from that for the sake of which he acts (to tinos heneka prattei) and not from the action he does (ti prattei) ... We praise and blame everybody with a view to the decision (prohairesis) rather than to the deeds (erga), even though the exercise [of virtue] is more choiceworthy than virtue itself. The reason is that people can do bad things (phaula) when compelled but no one can be compelled to decide. Further still, it is because it is not easy to discern the character of a decision that we are compelled to judge a person's character from their deeds.

This passage asserts that we often need to judge a person's character from their actions rather than from their decisions, since the ends for the sake of which the person acts are not obvious and, as Aristotle tells us elsewhere, people are not typically forthcoming about them either (Soph. Elench. 172b36-173a6). So, although we know - by observation - what people are doing (i.e. their actions), we do not (and mostly cannot) know the goals at which they aim by those actions simply in virtue 
of knowing what they are doing. All this might seem intuitive. We usually have little problem identifying what someone is doing even though we cannot tell why she is doing it. This seems to be, in fact, a precondition of our ability to navigate everyday life. For example, we can recognize that someone is donating to charity and yet not know whether she is trying to help people in need or whether she is just attempting to promote her political image. Similarly, we can recognize that someone is cleaning windows of a bank and yet not know whether he does it because he is being paid to do it by the bank or because he is a thief trying to scope the terrain.

However, one might also think that one actually does not know what a person's action is unless one knows her goal or purpose in doing what she is doing. Whether one is trying to help people in need or promote one's political image depends on the goal at which one aims in doing whatever it is that one is doing. In this sense, an action and its goal seem inseparable. ${ }^{37}$ In fact, Aristotle himself thinks that what a given change is (and action is a kind of change) is fixed by the goal of that change. ${ }^{38}$ So it would appear that we both know and do not know what people's actions are, depending on what we take 'action' to refer to - the easily recognizable acts of donating to charity or of cleaning windows, or those acts understood in the light of the goals the agents aim at by performing those actions.

We can bring clarity to this confusion by employing the results of the discussion of productive and practical reasoning. Let us take the example of giving money to charity. One can have various reasons or goals in doing so - one can do it out of the goodness of one's heart or to promote one's political image. In either case, however, it is a contingent matter that giving to charity will do as a way fulfilling one's desire either to do good or to promote one's political image. It is no surprise, then, that it is not possible to infer the reason one has for donating (or the goal one pursues by it) from the action of donating to charity itself. We have already discussed the contingent relation that obtains between one's desire and what one determines (by practical reasoning) would satisfy it. But we have also seen that Aristotle thinks that the result of practical thinking is a description of something about which one can reasonably ask 'How does one do it?' and as an answer expect a recipe - specified in universal terms - to tell one how. In our example, giving money to charity (as opposed to promoting one's political image or doing good) is a specific task for which there are specific steps to take in order to execute it. It is something that can be

\footnotetext{
37 This point was forcefully made by J. L. Ackrill, 'Aristotle on Action' (n. 35 above), 596.

${ }^{38}$ For a discussion of this point, see D. Charles, Aristotle's Philosophy of Action (n. 9 above), 19-27.
} 
specified in universal terms and done by anyone who has a reason for doing so, whether that person desires to help others or to improve her political image.

We can put the matter more technically. An action considered without the reference to its goal (as given by one's decision) is a description of what one does that specifies it as something which can become a goal for productive reasoning. It is something to be produced or made, a poieton. However, when the action is considered as something to be taken in order to satisfy a desire, as something done for the sake of some goal or end, it is a prakton - an achievement (for want of better terminology). Now, insofar as actions are poietta, they are objects of productive thinking (including craft and cleverness) and as such the only relevant considerations as to their being well done are their own qualities (NE 2.4, 1105a27-8). This follows from the fact that what makes them what they are can be specified without reference to any desires or beliefs - there are objective steps for how one can donate money to charity and what counts as having done so. But insofar as those actions are prakta, they are objects of practical thinking - they have been chosen as ways of satisfying a desire and what they are is determined by the desires they aim to satisfy.

There is a well-known and crucial objection to this account. Is not 'donating money to charity' already specifying something (say, transferring money) by its purpose? In fact, would not any description of action ultimately involve further goals of those actions? If so, the distinction between actions considered as poieta and prakta would surely collapse. This objection is in a way correct and it helps us to both clarify and further the argument. It is a feature of most publicly sanctioned activities, which include crafts and their objects, that they have a built-in purpose. This purpose is not a necessary consequence of engaging in them but, rather, a way of putting such activities or crafts to use in ways that the society came to recognize as useful for satisfying its needs and so decided to promote or enable them for that purpose. Thus the production of bread feeds the hungry, surgery saves lives and book-printing distributes knowledge. This is a lesson learnt in Metaph. 9.2, discussed above in Section 2 above: every craft has its proper purpose with which it is properly concerned. In fact, this purpose constitutes the goal for the sake of which a given craft exists - medicine for restoring health, shoemaking for allowing people to walk comfortably, and so on.

It is crucial to recognize that each craft has a goal for the sake of which it exists and that crafts and their activities are matters of public knowledge and interest. In $N E$ 1.1, Aristotle famously presents an image of a hierarchy of crafts - for example, there is bridle-making which serves horsemanship which, in turn, serves generalship, and so on (1094a7-14). As Aristotle portrays it, all or most human activities potentially are (or involve) exercises of various technai or 
(more generally) kinds of knowledge that fall under the general umbrella of cleverness. What people do in their daily lives is intelligible to us precisely because we recognize what they are doing as falling under such general, publicly recognized descriptions which we understand as tied to certain (good) purposes. We know that the baker is making food (and that food is for relieving hunger) and that the doctor is performing surgery (and that that is done to make people healthy). Of course, we need to learn to recognize people's activities in this way - we do so, for example, by becoming competent speakers of language or by becoming socialized and encultured through both private and public education and upbringing. For our purposes, the important point is that we learn to see human activities as purposeful, that is, as tied to particular purposes that we are, generally, able to recognize.

Interestingly, however, when we ordinarily see people engaging in such activities, we do not suppose that they engage in them because (or for the sake) of those societally built-in (good) purposes that predominantly benefit others rather than the people who do them. We do not think that the baker bakes bread to feed people or that the shoemaker makes shoes to help people walk, but rather that they want to sell the bread or the shoes to make a living. ${ }^{39}$ In other words, we suppose that people engage in the various activities they do because they want to further their own good, that is, they exercise their crafts for ulterior (often selfish) purposes. In fact, we find this view so appealing that when we think of what motivates people to engage in the such crafts and activities, we tend to forget about their built-in or original purposes. And so the only contrast that comes to mind is that of engaging in them for their own sake (i.e. abstracting from any further purpose) and for ulterior purposes (i.e. especially for sake of one's own good). That particular contrast, rather obviously, weights things towards the latter case: simply making bread or repairing cars for its own sake does not appear either sensible or desirable (setting aside cases in which these are one's hobbies).

But notice what would happen if one were in fact to do such craft-activities for those original, built-in purposes - for example, if the baker were to bake bread in order to feed the hungry, the car mechanic repair cars in order to help distressed motorists, and the doctor perform surgery in order to heal the patients. Suddenly, their activities - the exercises of their respective crafts - get a very different flavor. They appear to have what we might call moral or intrinsic value. Interestingly, they appear to do so because they are done for the very reasons (or very purpose or utility) for which they came to exist. This is neither a case of doing the activities (say, baking bread)

\footnotetext{
${ }^{39}$ This is an old point, made by Thrasymachus (Plato, Rep. 343b-344c).
} 
for their own sake (in the sense just described, that is, for example, so as to make bread) nor doing them for ulterior (mostly selfish) purposes. Rather, it is engaging in them in a way that is proper to those crafts of which they are exercises. This is, I take it, Aristotle's point. Deciding on actions 'for themselves' ( $d i$ ' auta) does not mean deciding on them independently of the goal that the actions aim at. Rather, he means that one has to decide on them for the very reasons for which such actions or activities and the crafts associated with them exist and are publicly recognized as good and useful. To decide to make bread for itself is not to decide to make bread for the sake of making bread (the insensible option mentioned above) but, rather, for the sake of feeding those who are hungry. This is what bread-baking is.

We can put this account in terms of the difference between actions understood as poietta and as prakta. One can bake bread or make shoes (these are poieta, things one can do according to appropriate recipes) for various reasons. But when one is motivated to bake bread or make shoes by the very purposes for which such activities exist (to feed the hungry, etc.), one is said to have decided one those actions 'for themselves' - one's prakta reflect the original, built-in value of one's chosen poieta since one desires to do them for the very reasons for which they exist.

Can this account be applied to virtuous actions? Virtuous actions (as opposed to exercises of crafts) are a special subclass of human activities - they promote particular, especially exalted or useful goals: for example, just actions are those that contribute to equitable distribution, generous ones those that benefit other people, brave those that, among other things, contribute to the preservation of the polis, and so on. These actions are recognized as especially worthwhile or noble (kala) since they are difficult and their goals or results are especially beneficial to the agent, fellow citizens or the society (this aspect of kala actions is very explicit in Rhet. 1.9, 1366a33-b22). Moreover, unlike in the case of craft-like productions (which too can be done for themselves, that is, for the good, useful purposes in the way I just explained), there is usually no particular way in which the virtuous goals can be promoted - for feeding the hungry or healing the sick we have farming and medicine, but there is no particular craft for benefitting those in need or for preserving the polis. Sometimes we benefit those in need by donating money, but at other times by baking bread. Similarly, sometimes it is fighting that preserves the polis, but at other times it is doing good journalism. In other words, in order to be a good, praiseworthy craftsman, one only needs to exercise one's craft for the purpose for which it exists. This, although admirable, is not especially difficult. In order to be a virtuous person, however, one not only has to act for the right, kala purposes (say, equitable distribution, benefitting those in need, preserving the polis) but also be able 
to determine which activities would do that - and that is a difficult task, since there are no activities particular to bravery or generosity, as there are for medicine or bread-making.

Nevertheless, the idea remains the same - to decide on virtuous actions for themselves just is to decide on them for those features that make them virtuous, that is for those features that contribute to the virtuous, noble goals. Aristotle tells us what those goals are in each case (for temperance it is health, for generosity benefitting those in need, for bravery preserving the polis, and so on). The generous person, then, is one who, say, donates money to charity or spends a year teaching mathematics precisely so as to benefit those who need it - she decides to donate or to teach because it is beneficial to the right people not because she wants to donate for the sake of donating or teach for the sake of teaching. ${ }^{40}$ Notice that this does not mean that one has to decide to, say, stand firm in battle because one believes or thinks that virtue (courage) demands it. Rather, it means that one does so for those reasons (like saving the polis or preserving an equitable distribution of wealth) that make such actions just or courageous. Of course, the virtuous agent might well care about her temperance or courage or virtue in general and cultivate it. This is important especially in teaching others (say, children) about virtue. But this does not exclude that she is genuinely motivated by the virtuous goals themselves (rather than, say, by her awareness of them being virtuous or by preserving her own virtue).

Finally, when Aristotle says that one who performs virtuous actions virtuously must have knowledge, what knowledge does he have in mind? And why does he think that it counts for (almost) nothing in the case of virtue? If the foregoing account is correct, then (1) it cannot be knowledge of what makes one's actions virtuous, since such knowledge is needed (and so crucial) in order to decide on one's actions for themselves; what makes one's actions virtuous must constitute one's reasons for doing them (i.e. this knowledge is part of the second of the three conditions enumerated at 1105a31-3). It also cannot be (2) the knowledge one needs to translate one's overall goal (say, helping Luca) into a decision to do something specific (e.g. to build a house as a way of helping Luca) since such knowledge is required if one is to make a decision at all. ${ }^{41}$

\footnotetext{
${ }^{40}$ On my interpretation, there is thus no special problem about virtuous actions having what some have called 'external goals' (e.g. NE 10.7, 1177b16-20) while being ends in themselves (e.g. NE 10.6, 1176a35-1177b9), since to decide on such actions for themselves is just to decide on them for those 'external' goals. For a discussion of the problem, see J. Whiting, 'Eudaimonia, External Results, and Choosing Virtuous Actions For Themselves', Philosophy and Phenomenological Research 65 (2002), 270-90.

${ }^{41}$ Iakovos Vasiliou, 'Virtue and Argument in Aristotle's Ethics' in S. Tenenbaum (ed.) New Trends in Philosophy: Moral Psychology (Amsterdam, 2001), 37-78, argues that the knowledge in question is knowledge of 'what ought to be done' (55). Such knowledge, however, is expressed in (and part of) one's decision and so belongs to the second condition.
} 
Finally, it cannot be (3) knowledge that what one does is virtuous (i.e. knowing that it is, say, courageous) since such knowledge is not needed for doing virtuous actions virtuously (at least not on the account I have just defended).

It remains that the relevant knowledge is knowledge of how to implement one's decision (in our example, knowledge of how to build a house, not knowledge of how to help Luca). ${ }^{42}$ This would fit the analogy with craft as Aristotle uses it in the $N E 2.4$. For example, if the virtuous thing is donating money or teaching mathematics, then it is knowledge of how to donate money or how to teach mathematics. In other words, the requisite knowledge would belong to craft or, in general, cleverness. If so, we can explain why it is both among the conditions of doing a virtuous action virtuously but also why it matters only very little in virtue, as opposed to craft. It matters in craft because craft just is that kind of knowledge, and to act with craft is to act out of such knowledge. It is among the conditions for acting virtuously, since if one did not know (at all) how to do what one decided to do, then the only way in which one could have performed the virtuous action would be by chance or by following someone else's instructions. It is thus a necessary feature of acting virtuously. Yet it matters little because it has to do with the ability to do what one decided to do rather than with one's motivation to do it. In fact, the requisite knowledge can be quite minimal. For example, although one may not know how to carry out what one decided to do (say, build a house or teach mathematics), as long as one knows how to elicit the help of others who do (i.e. how to hire a house-builder or elicit help of friends who know mathematics), one knows all one needs to know. One can, as Luca did in our example with Joe, outsource the thing to be done and yet remain the one who acted in a virtuous way. ${ }^{43}$

\footnotetext{
${ }^{42}$ Vasiliou, 'Virtue and Argument' (n. 42 above), 55, objects to this idea since he thinks that if the knowledge condition was meant to capture the requisite expert knowledge, then in the case of virtues it would have to be the expert moral knowledge and such knowledge would not count 'little or nothing'. But it is not necessary to think that Aristotle has in mind moral knowledge (expert or not) as opposed to (as I have argued) knowledge of the sort that is relevant to crafts or, in general, cleverness. My interpretation is thus closer to Bernard Williams' claim that it is 'everyday knowledge relevant to effective intentions, as it is with technai' ('Acting as the Virtuous Person Acts' in R. Heinaman, ed., Aristotle and Moral Realism, Boulder, San Francisco, 1995, 13-23 at 15), although I am unsure whether he means the same idea. Vasiliou (loc. cit.) certainly interprets Williams as saying that the knowledge in question is merely 'the knowledge that what I am doing is building a house' rather than the expert knowledge of how to build a house. However, Williams is already assuming a situation in which one chooses to exercise a craft ('Acting as the Virtuous Person', 14), so it is possible to interpret him differently.

${ }^{43}$ I would like to thank Naly Thaler, Luca Ferrero, and the anonymous reviewer for many valuable comments.
} 